\title{
İnsansız hava araçları (İHA) İle enerji nakil hatlarının ölçülmesi üzerine derleme
}

\author{
Atilla Karabacak*1 \\ 1 Mersin Üniversitesi, Teknik Bilimler Meslek Yüksekokulu, Mimarlı ve Şehir Planlama Bölümü, 33150, Yenişehir/Mersin
}

\author{
Anahtar Kelimeler \\ İHA \\ Yüksek Gerilim \\ Enerji Nakil Hattı \\ Uzaktan Algilama \\ Fotogrametri
}

\begin{abstract}
ÖZ
Modern yaşamda insanlar her alanda elektrik enerjisine ihtiyaç duymaktadır. Santrallerde üretilen elektrik, şehirlere yüksek gerileme dönüştürülerek taşınır. Elektriğin bu yolculuğu iletken teller ve taşıyıcı direklerle nakil hatları üzerinden sağlanır. Enerji hatlarında olabilecek arızalar ekonomiye, üretim gücüne ve canlı yaşamına zarar verir. Enerji hatlarının sürekli kontrol altında tutulması olası sorunları en aza indirecektir. Geleneksel insan gözlemi çok zaman alır, insanlı helikopterlerle yapılan gözlemler pahalı ve helikopter içindekilerin olası bir kazada yaşamını yitirmesi riskini taşır. Bugün için en etkili, objektif ve hızlı yöntem olarak insansız hava araçları (İHA) önerilir.
\end{abstract}

\section{Compilation on measurement of energy transmission lines with unmanned aerial vehicles (UAV)}

\author{
Keywords \\ UAV \\ High Voltage \\ Energy Transmission Line \\ Remote Sensing \\ Photogrammetry
}

\begin{abstract}
In modern life, people need electrical energy in every field. The electricity produced in the power plants is transported to the cities by converting it to high voltage. This journey of electricity is provided by conducting wires and carrier poles over the transmission lines. Faults in power lines damage our economy, production power and living life. Keeping energy lines under control will minimize potential problems. Traditional human eyes take a lot of time, observations made with manned helicopters are expensive and carry the risk that the helicopter contents will die in a possible accident. Today, unmanned aerial vehicles (UAV) are recommended as the most effective, objective and fast method.
\end{abstract}




\section{GíRiş}

Bir toplumun gelișmișlik düzeyi ve üretim gücü kullanılan enerji miktarından anlaşılabilir. Ülkelerin tam bağımsız olması kendi elektriğini üretmesiyle başlar. Santrallerde üretilen elektrik sanayinin lokomotifi olur, şehirleri aydınlatır, ülkeyi kalkındırır. Ürettiğimiz enerjiyi ülke içinde ihtiyaç duyulan yerlere güvenle taşımamız gerekir. Santralden çıkan elektrik yüksek gerilime dönüştürülerek iletilir. Şehirlere ulaşan elektriğin trafolarda gerilimi düşülerek şehir içi hattına verilir. Santrallerden çıkan elektrik Enerji Nakil Hatları (ENH) ile taşınır. ENH'ı doğa olaylarından etkilenir ve zarar görür, bunun haricinde de periyodik kontroller ve bakımlarının yapılması gerekir. ENH yanlış topraklama sonucunda yangın çıkarır.

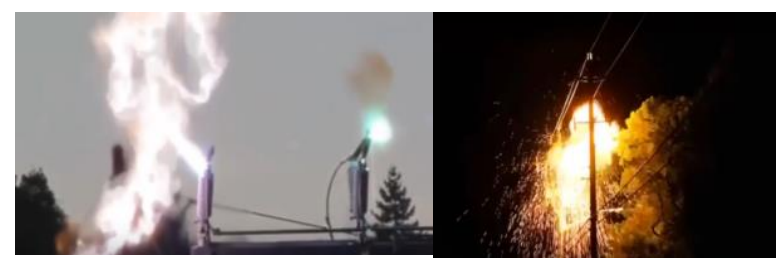

Şekil 1. ENH'da yangın çıkma anı (URL-6)

ENH kontrolleri insanların bizzat giderek gözlemleri veya helikopterle gidilerek yapılan ölçüm ve gözlemlerle yapılmaktadır.

Günümüzde bu ENH ölçüm işlerin İnsansız Hava Araçlarıyla (İHA) yapılabildiğini göstermek için bu çalışmayı yapmaya karar verdik. İHA'nın harita mühendisliğinde çok büyük yenilikleri getireceğini görmekteyiz.

\section{ENH GENEL BAKIŞ}

\subsection{Türkiye'nin Hidroelektrik Santralleri}

Türkiye enerji ihtiyaçlarını hidroelektrik, termik, rüzgar ve gelecekte Mersin'de yapımı süren Akkuyu nükleer enerji vb. santrallerden karşılamaktadır.

Türkiye enerji ihtiyacını karşılayan hidroelektrik santrallerinin dağılımı incelendiğinde ülkemizin doğu tarafında yoğunlaştığı şekil 2'de görülmektedir. Enerji ihtiyacının da nüfusun yoğun olduğu batı bölgemizde olduğu söylenebilir, dolayısıyla elektriğin Türkiye'nin bir ucundan diğer ucuna taşınması gerekir.

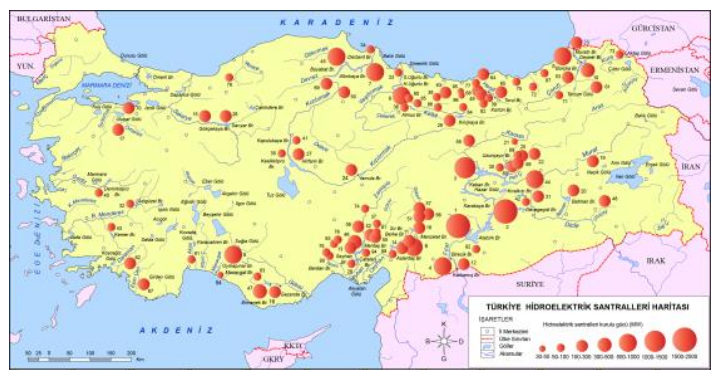

Şekil 2. Türkiye hidroelektrik santralleri 2016 (URL-2)
Santrallerden çlkan enerji şehirlere yüksek gerim hataları ile taşınır. Yüksek gerilim hatları, direkler, iletken teller, bağlantı elamanları vb. oluşur

\section{2. Örnek Elektrik Taşıma Elamanları}

Santrallerde üretilen elektrik iletken tellerle tașınır. Aşağıdaki iletken alüminyum tel ve sağlamlık için ortası çelik tel şeklinde kullanılmaktadır (şekil3).

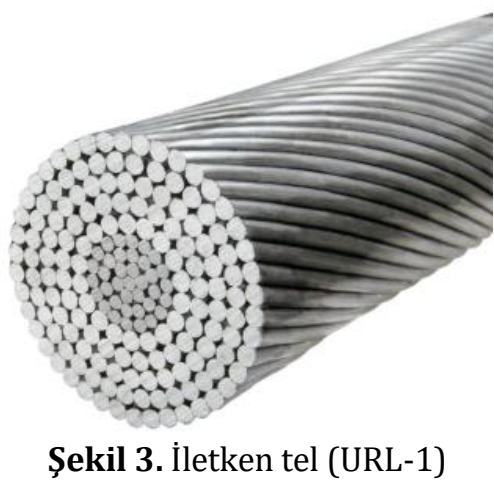

Santrallerden çıkan elektrik yerine göre farklı direklerle taşınır (şekil-4).

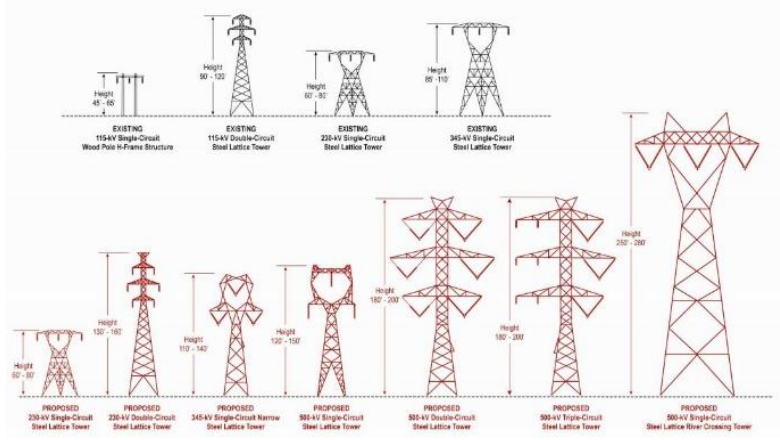

Şekil 4. Yüksek gerilim direk çeșitleri (URL-12)

Yüksek gerilim direklerin en üstündeki teller enerji taşımaz topraklama ve iletişimi sağlamak görevi olan tellere koruma iletkenleri denir (şekil-5).

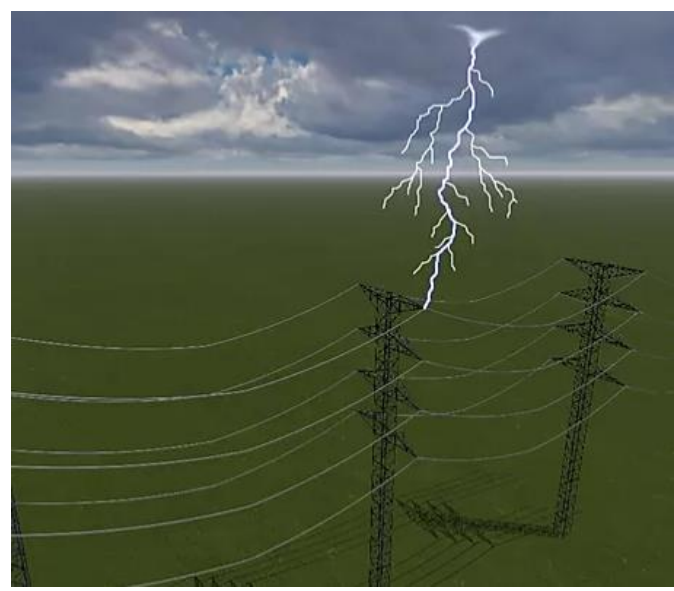

Şekil 5. Enerji taşımayan koruma iletkenleri (URL11)

ENH kullanılan iletkenlerin, direklere tespitine yarayan ve iletkenleri hem tutmaya hem de toprak ile diğer iletkenlere karşı izole etmeye yarayan cam 
veya seramikten yapılan malzemelere izolatör denir (Şekil-6).

Ark boynuzu kısa devre veya ark atlamasında izolatörü korur (șekil-6).

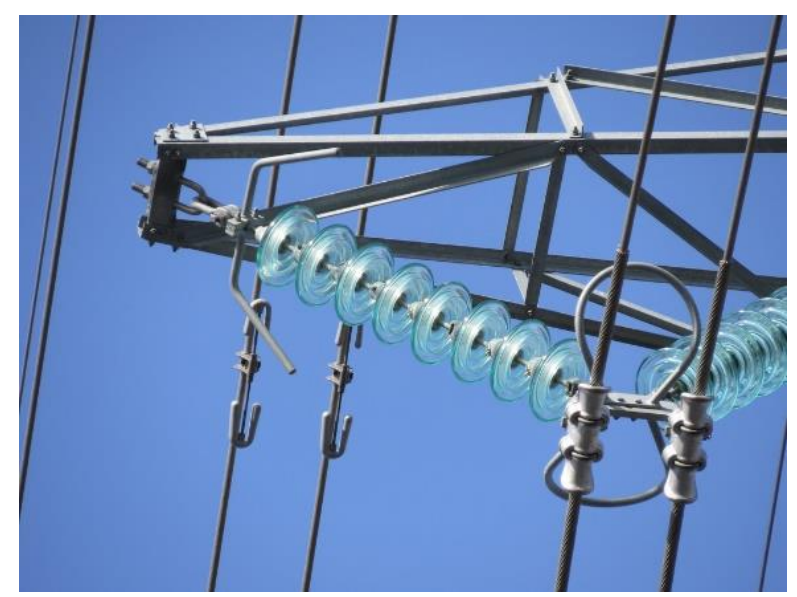

Şekil 6. Ark boynuzu ve izolatör (URL-13)

İzolatör de oluşan arkın topraklanması ark koruma halkası yapar (şekil-7)



Şekil 7. Ark koruma halkası (URL-1)

Demet spacer, aynı fazdaki tellerin birbirine değip zarar vermemesi için konur (șekil-8).

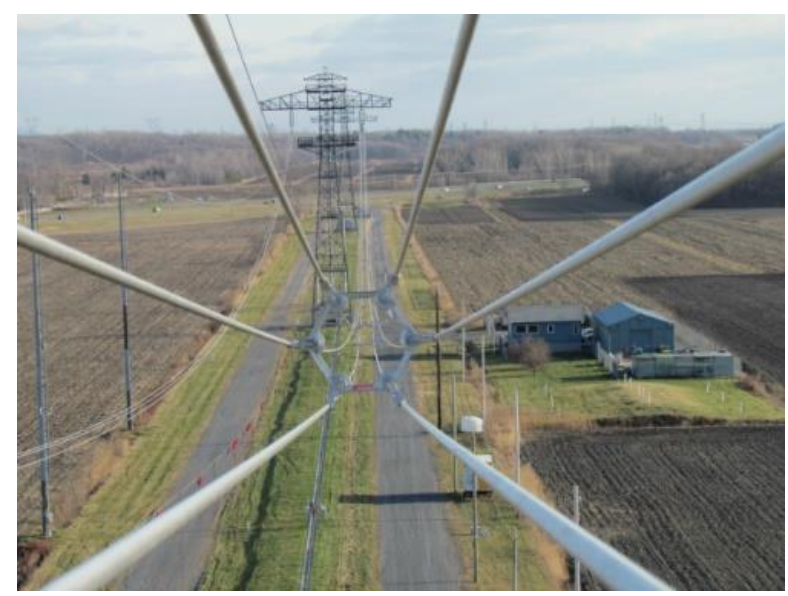

Şekil 8. Demet spacer (URL-1)
Tellerde oluşan titreşim damperle durdurulur (şekil-9).

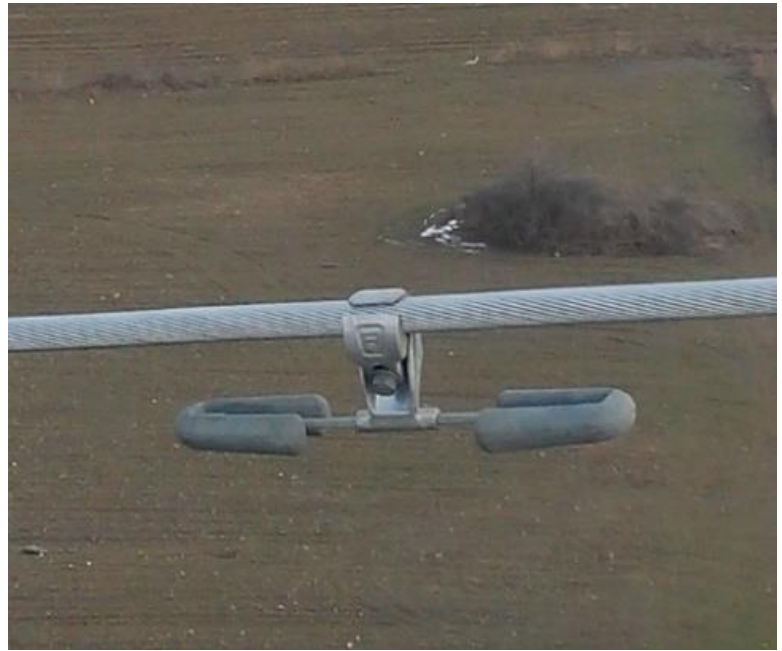

Şekil 9. Damper (URL-1)

\section{YÖNTEM}

Çalışmada; Luque-Vega L. ve ark. tarafından 2014 yılında yayınlanan "İnsansız hava araçlarıyla enerji nakil hatlarının denetimi" makalesinde insansız helikopterle ENH denetimi için tasarladığı sistem incelendi.

Deng, C. ve ark. tarafindan 2014 yllında yayınlanan "İnsansız hava araçlarıyla enerji nakil hatlarının muayenesi" makalesinden farklı IHA'ları nasıl birlikte kullandığına bakıldı.

Jaugılas, J. tarafindan 2019 yılında yayınlanan " Yüksek gerilim üzerinde uçan bir İHA'nın șarz edilmesi" makalesinden İHA'nın tellere değmeden şarz edilebilirliğinden yararlanıldı.

ERBAȘ M., tarafından 2016 yılında yayınlanan "LiDAR Verilerinden enerji nakil hatlarının otomatik tespit edilmesi çalışmaları" makalesinden yararlanıldi.

Teng, G. E. ve ark. tarafından 2017 yllında yayınlanan " Mini İHA ile güç hattı Muayenesi" makalesinde, Çin'de yaptıkları ENH ölçümlerinden yararlanıldl.

Guan, H. ve ark. tarafından 2015 yllında yayınlanan" Güç iletim hatlarının araç kaynaklı lidar verilerinden çıkarılması" makalesinden yararlanılmıștır.

Chen, C. ve ark. tarafindan 2018 yllinda yayınlanan, "IHHA kaynaklı LIDAR verilerini kullanan iletim hattı koridorları için otomatik boşluk anomali tespiti" makalesinden yararlanılmıştır.

Xiaojun S. ve ark. tarafindan 2018 yılında yayınlanan "Yüksek gerilim hatları için LiDAR nokta bulut verisi otomatik çıkarma algoritması" makalesinden yararlanılmıștır.

\section{ENH ÖLÇMELERI}

ENH ölçmeleri sadece kontrol değil hatlarla ilgili tüm aşamalarda kullanılabilirliğini aşă̆ıda açılklamaya çalıştık. 


\subsection{ENH Sahasının Haritalanması}

Enerji Nakil hatlarının geçeceği koridor sabit kanatlı İHA ile taranarak halihazır haritası elde edilir. Harita üzerinde belirlenen eğime göre some noktaları ve aliyman belirlenir, daha sonra belirlenen aralıkta direk yerleri belirlenir. Kamulaştırma planları hazırlanır. İrtifak hakkı kurulacak özel mülkiyet arazileri belirlenir.

\subsection{ENH Direklerinin Aplikasyonu}

ENH aplikasyonunda da Drone kullanılabilir. Şöyle ki klasik yöntemle nirengi noktaları döşenmesi gerekir. Gezici GPS kullanarak aplikasyon yapılabilir, ancak arazi ormanlık veya bina gibi engeller varsa GPS in kullanımı zor olacaktır. Bunun yerine önerimiz Drone monte edilmiş bir lazer işaretleyici ile direk konumlarına yönlendirilen bir Dronenun lazer işareti ile aplikasyonu yapmak olacaktır, bu yöntemi daha önce yapana rastlayamadık, bu şekilde bir İHA tasarlamayı düşünüyoruz yapılabilir olduğunu bildiğimizden sistem tasarımı için öneriyoruz. Aksi halde görüş olması açısından çok ağaç kesilebilir.

\subsection{ENH Bildirilme Zorunluluğu}

ENH ve yüksek yapılar alçak uçuş yapan hava araçları için tehlike oluşturur. Askeri Coğrafya Hizmetleri Yönetmeliğinde düşey engeller yerleşim yerlerinde 60 m'den, dışında 30 m'den yüksek olan yapılardır. ENH bu kapsama girmektedir. İnsan eseri olan düşey engeller, burada belirtilen sınırlara ulaştığında Harita Genel Komutanlığına (HGK) bildirilmesi gerekir. HGK'da bildirimler sayesinde düşey engeller veri tabanı güncellenir (Erbaş, 2016).

Yüksek gerilim taşıyan ENH bildirme zorunluluğu nedeniyle de haritalanması gerekmektedir. Hava lidarı ile alınan çok sayıda nokta verisi işlenerek şekil.10'da gösterilen harita elde edilir, siyah hat $15 \mathrm{~m}$, kırmızı hat araziden $30 \mathrm{~m}$ yükseklikteki ENH'larını temsil etmektedir (şekil10).

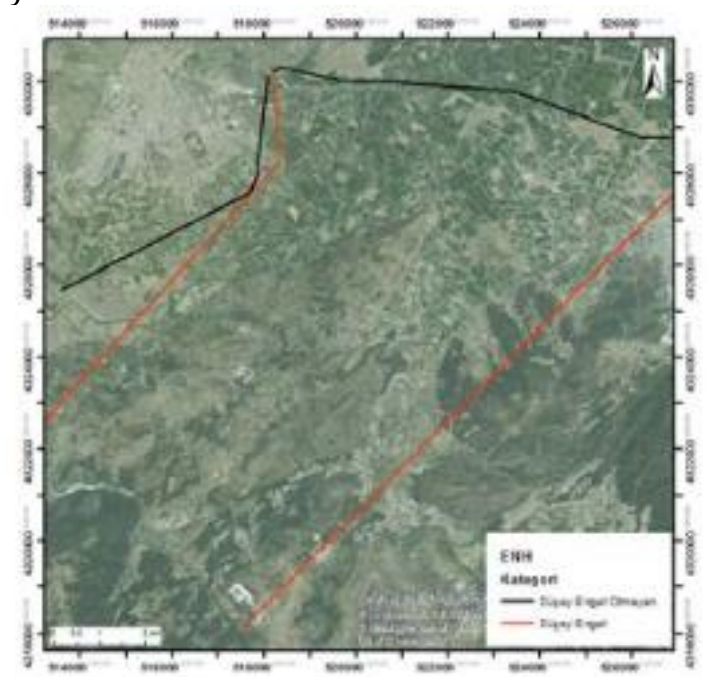

Şekil 10. ENH gösterimi (Erbaş, 2016)

\subsection{ENH Ölçme Yöntemleri}

ENH ölçmelerinde dört yöntem öne çıkmaktadır. Bunlar yaya insan devriyesi, insanlı helikopter, tırmanma robotu ve İHA yöntemleridir.

\subsubsection{Yaya insan devriyesi}

Bir pilondan (Yüksek gerilim tașıyan büyük direk) diğer pilona kadar iki kişilik bir ekibin ENH incelemesidir. Görsel inceleme, dürbün yardımıyla ve bazen de kızılötesi ve korona (iletken etrafında bir sıvının iyonlaştırılmasıyla oluşan elektrik deşarjıdır, iletken etrafında mor bir halka görülür ve korona olayı iletim hattına zarar verir) (şekil-11) algılama kameraları ile gerçekleştirilir. Yerden gözlenebilen alanlarda başarıyla uygulanır. Personelin direkler arasında gitmesinde karayolu bulamamaları işi zorlaştırır. Yöntem yavaş, sıkıcı, monoton ve özneldir, bu yüzden bazı arızalar göz ardı edilebilir. (Luque-Vega vd., 2014)

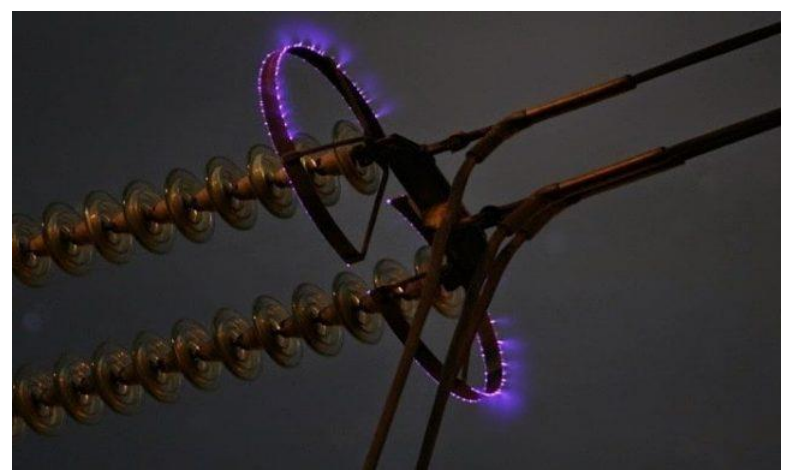

Şekil 11. İletken etrafında olușan korona olayı (URL. 3)

\subsection{2. İnsanlı helikopter devriyesi}

Helikopter destekli inceleme, üç kişilik bir ekip, pilot, müfettiş ve kayıt cihazı ile sabit veya rotor kanatlı uçaklar tarafından gerçekleștirilir (şekil-12). Hasar ve mevcut durum etkili șekilde belirlenir. Yöntem hızlı ve her yere yetişme kapasitesi yüksek olması avantajlarıdır. $\mathrm{Bu}$ yöntemin maliyeti yüksektir onun için ulaşılması zor yerlerde tercih edilmesi akılcı olur. $\mathrm{Bu}$ yöntem insan hayatını tehlikeye attığından alternatif tırmanma robotları veya İHA'lar araștırılmaya bașlanmıștır. (LuqueVega vd., 2014; Karabörk vd., 2009; Yakar vd., 2016; Yiğit ve Uysal, 2019)

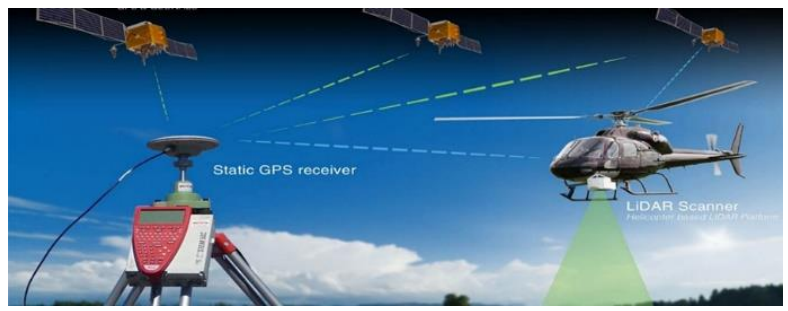

Şekil 12. Lidar eklenmiş insanlı helikopter (URL. 4) 


\subsubsection{Tirmanma robotu}

Bir mobil robot iletken boyunca hareket edebilir ve güç hatlarındaki çeşitli sorunların üstesinden gelebilir. Bu yöntemin ana avantajı, hatta olan yakınlığı ile gelen denetim hassasiyetidir. (Luque-Vega vd., 2014)

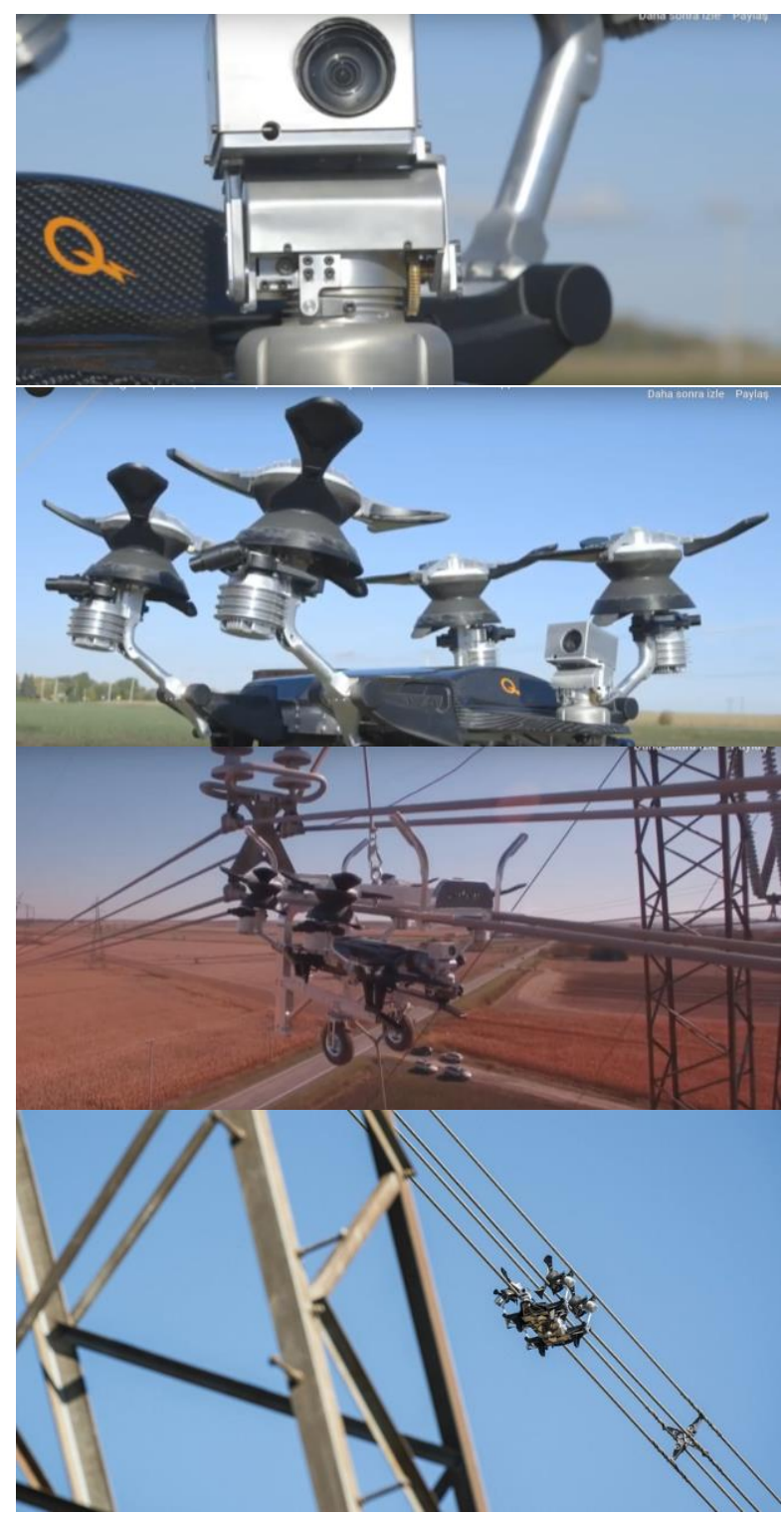

Şekil 13. ENH tırmanma robotu (URL-10)

Kanada'da bulunan Hydro-Quebec enerji şirketi 2019 yılında yüksek gerilim hatlarına hata ayıklamaları için tırmanan, LineRanger robotunu geliştirdi (şekil-13). Robot 50kg ağırlığında uzaktan kumanda ile yönetilir, yüksek gerilim direklerine asılı olarak hareket eder, izolatör gibi engelleri geçebilir. Robot operatörün hatları görmesi için HD kameradan gerçek zamanlı bir video aktarır. Robot üzerinde yerleștirilen sensorlar, ısınma ve korozyon noktalarını tespit eder, bağlantı noktalarındaki direnci tahmini olarak bildirir. Bütün bu özellikleri nedeniyle zaten kullanılan İHA'ına ciddi bir rakip olduğunu söyleyebiliriz (URL-10).

\subsection{4. İHA}

Birçok ENH kontrolü yapan firmalar tek tip İHA kullanmakta buda farklı özellikleri karşılayamadığından yetersiz kalmalarına yol açmaktadır. Sabit kanatlı İHA'lar hızlı uçuyor, uzun bir ENH ön incelemesi için uygun olmaktadır, ancak elektrik direklerinde, kablolarda ve izolatörlerde alt kısımların kusurlarını göremez (şekil-14). Dronlar nesnelere yaklaşarak resim çekebilir bu sayade ayrıntılı inceleme yapılabilir (şekil-15), (Deng vd., 2014; Şasi ve Yakar, 2018; Mirdan ve Yakar, 2017; Yiğit ve Ulvi, 2020; Kaya vd., 2021).

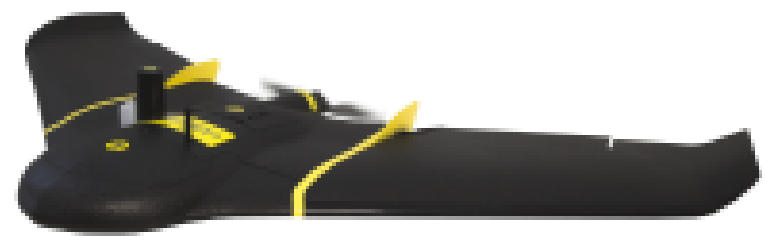

Şekil 14. Sabit kanatlı İHA (URL. 5)

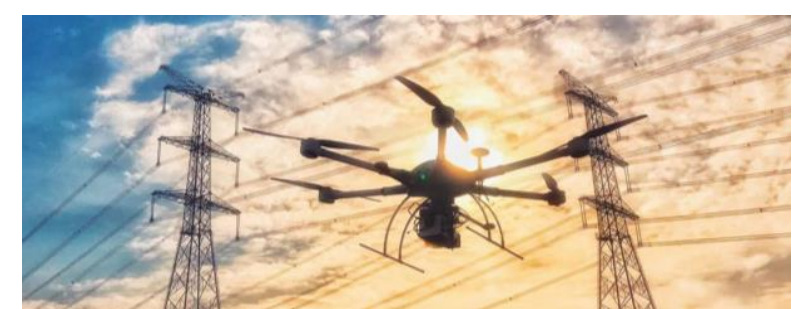

Şekil 15. Dron (URL-7)

Sabit kanatlı İHA'da bir rota oluşturulur ve otomatik planlı uçuş gerçekleştirilir, inişten sonra hafıza kartından resim ve videolar alınır. Uçuş sırasında veri bağlantısı yoktur. $70 \mathrm{~km} /$ saat hızla 50 $\mathrm{km}$ boyunca devriye atabilir. Dronlar bir uzaktan kumandayla görebildiğimiz aralıkta yönlendirilebilir (Alptekin vd., 2019; Yiğit vd., 2020; Çelik vd., 2020; Şenol vd., 2020; Polat ve Kaya, 2021).

Sabit kanatlı İHA ENH'nın 100-200 m üzerinde uçar, geniş açılı bir kamera ile görüntü alır ve bu sayede çöken direk, kırılan tel, tellere yaklaşan ağaçları kolayca görür. Yakalanan kusurları ayrıntılı incelemek için dron uçurulur. Dron otomatik pilot ve GPS/ IMU navigasyon sistemi kullanır. Dron havada asıl durabilir ve dikey uçabilir ve bu sayede kontrol biriminden ayrintılı inceleme yapılabilir. Pil gücünden dolayı 25 dakika havada kalır ve $5 \mathrm{~km}$ uçabilir (Deng vd., 2014; Ulvi vd., 2019; Alptekin vd., 2018; Şenol vd., 2017; 2019; Kaya ve Polat, 2021).

İHA'nın enerji sorunlarıla ilgili JAUGILAS John ENH'dan dolaylı olarak kendini şarz eden İHA modellemiştir. Yüksek gerilim hatlarından yayılan elektro manyetik alanda İHA'ya yerleştirilen bir bobin üzerinde şarj akımı oluşturarak İHA'nın sürekli şarj edilebilmesini önermiștir. İHA'ına bir çarpma sensörü yerleştirilir. Bir uçuş planına göre uçan İHA direk ve tellere güvenli mesafede şarz mesafesinde durur ve bataryasını doldurarak işe devam eder. ENH haricinde de enerjisi azalan İHA'ları bu sistemle enerjisi azaldığında ENH hattına 
giderek enerjisi doldurup farklı amaçlarda sürekli çalışabilir ( Jaugılas, 2019; Ulvi vd., 2020; Kabadayı vd., 2020 ).

ENH '1 ölçmeleri büyüyen bitki örtüsünün algılanması, tellerdeki sarkmaların belirlenmesi ve termal değerlendirmelerin yapılıp risk noktalarının belirlenip direklerin konum bilgileri, iletken hat bilgilerinin coğrafi bilgi olarak sunulması gerekir.

Termal kameralı dronlar ENH ayrıntılı incelemesinde kullanılabilir (şekil-16).

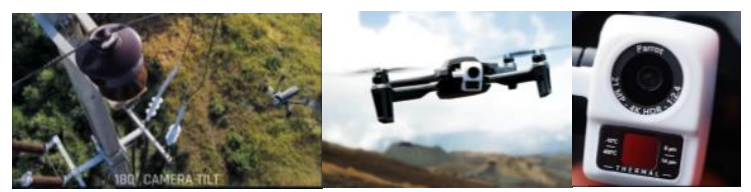

Şekil 16. Termal kameralı dron -10 ile $+400{ }^{\circ} \mathrm{C}$ de çalışabilir (URL. 5)

Yerde kullanılan mobil LİDAR ile de ENH modellenebilir, ancak ormanlık ve sarp arazilerde hareket etmek zor olacağından çözüm olmaz. (Teng vd., 2017)

Luque-Vega ve arkadaşları 2014 yılında yaptıkları bir çalışmada; Meksika'da ENH ölçümü için bir İHA sistemi tasarladılar. Bir drone üzerine termal kamera, renkli kamera, mikroişlemci, aletsel ölçüm birimi (IMU), GPS, altimetre, iletişim sistemi ve oto pilot ile donatmışlardır. Drone uçuş kontrolünü üç farklı șekilde yapabilecek șöyle; manuel uçuş, GPS sabit konumu ve GPS navigasyon yöntemlerdir.

- Manuel uçuş da drone kullanıcı tarafindan yönlendirilir.

- GPS sabit konumu da kullanıcı manuel uçuşta uçarken GPS konumunu korumaya çalışır.

- GPS navigasyonun da drone, kullanıcinın tanımladığı GPS koordinat yolunu izleyerek otonom uçuş gerçekleştirir (şekil-17).

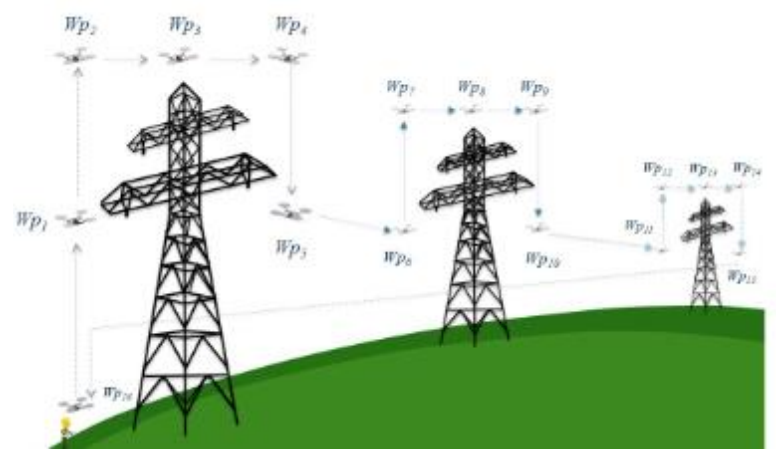

Şekil 17. ENH'nın dronela ölçmelerinde örnek konum modeli (Luque-Vega vd., 2014)

Uçuş sırasında çekilen görüntüyü anten yer kontrol noktasına iletir. Pilot görüntüleri izleyerek gerektiğinde drona komut verir (şekil-18).

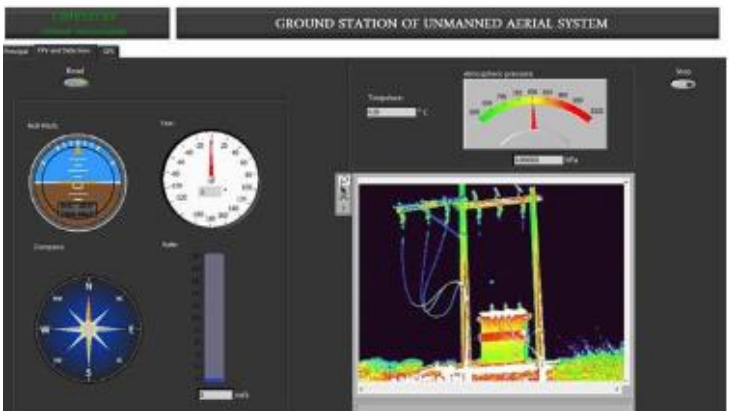

Şekil 18.Yer kontrol noktasındaki bilgisayar ekranı (Luque-Vega, vd., 2014)

Yer istasyonundaki bilgisayarda iki kamera görüntüleri birlikte değerlendirilir. ENH'nın bağlantı noktalarındaki bağıl sıcaklık karşılaștırılır. ENH'nın üç ekleminde elektrik direncindeki artış, eklemdeki sıcaklıkla doğru orantılıdır. Dolayısıyla ENH'nın üç eklemindeki sıcaklık farkı tespiti arıza tespiti için yeterli olmaktadır. Termal görün arka planı kaldırıldığında sıcaklık farkı varsa arıza vardır. (Luque-Vega, vd., 2014).

Havadan toplanan nokta bulutu verilerinden ENH hatları incelenir. ENH'nın Lidar verileri Microstation programıyla üç boyutlu modellenebilir, üzerinden istenen ölçüler alınabilir (şekil-19).

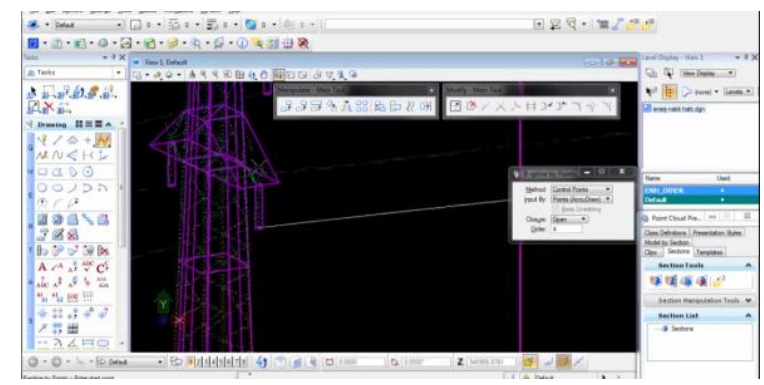

Şekil 19. Microstation programıla ENH çizimi (URL-8)

Program ile Lidar nokta bulutundan ENH yükseklik ve sarkmaları belirlenebilir (şekil-20).

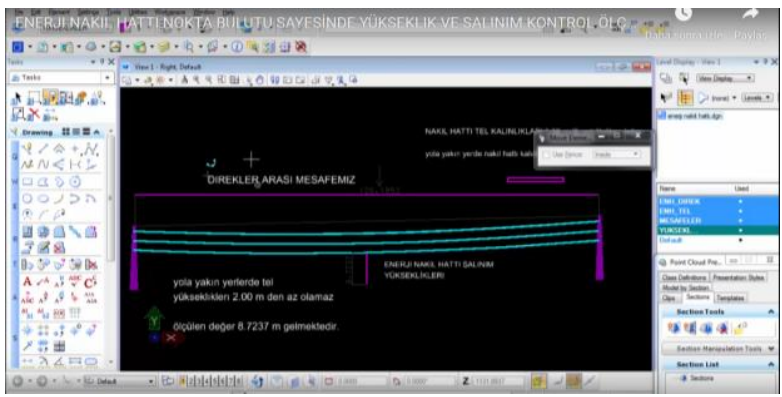

Şekil 20. Microstation programıla tel sarkmaları ve yüksekliklerin modellemesi (URL-8)

ENH'nın yüzeye ya da ağaçlara yaklaşması topraklamaya yol açarak yangına neden olur, doğa ve insanlar için bir tehdit oluşturur. Çin'de ortalama olarak, ağaçlar tüm elektrik kesintilerinin yaklaşık \% 30'unun sebebidir (Guan vd., 2016). Çin'de yapılan bir çalışmada 2500 km'lik ENH hattında Şekil 21'de 
kırmızı nokta ile işaretlenen 40 tane tehlikeli nokta işaretlenmiştir. (URL-9)

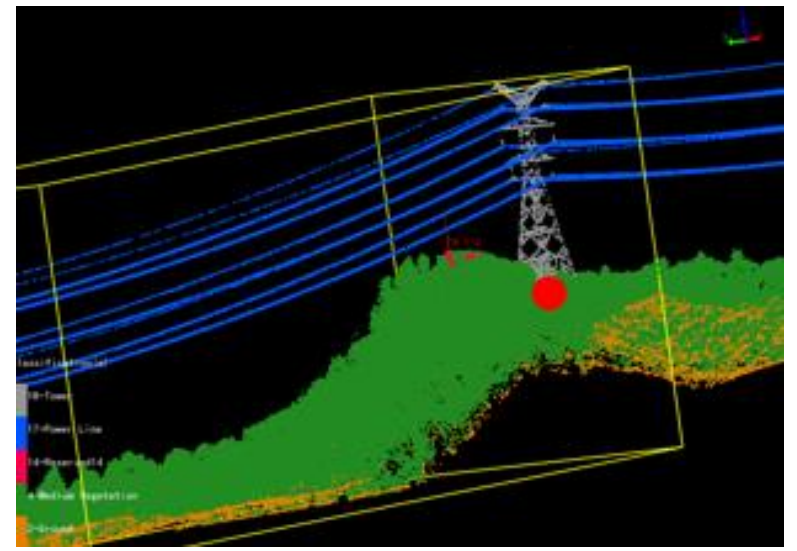

Şekil 21. Lidar görüntülerinden elde edilen tehlikeli nokta (URL-9)

Chen ve arkadaşları Çin'de yaptıkları bir çalışmada ENH ile yüzey ve ağaçlar arasındaki mesafeleri hava Lidarı ile dm doğruluğunda ölçmeyi başarmışlardır (Chen vd., 2018)

Shen ve arkadaşları Çin'de İHA lidar ile nokta bulutundan ENH'nın, ayrılabilmesi için otomatik bir uzay tasarlayarak ENH hat ve direklerini konumlandırmayı başarmışlardır (Shen vd., 2018)

Deng ve arkadaşları Çin'de yaptıkları bir çalışmada geleneksel yöntemlerle bir haftadan uzun sürecek bir ENH denetimini farklı İHA'nı birlikte kullanarak 3 saatte tamamlamışlardır (Deng vd., 2014)

\section{SONUÇLAR}

ENH proje uygulanmasından, işletilmesi sirasında kontrollerinde İHA ve tırmanma robotları kullanılabilir. İHA'nın en büyük avantajı hızlı olmasıdır. Sabit kanatlı İHA ile drone birlikte kullanılması avantajlar sağlayacaktır. Sabit kanatlı İHA ile ön inceme yapılmalı şüpheli noktalar termal kameralı dronla incelenmesi tespitleri hızlandıracak etkili bir denetim sağlanacaktır. İHA'nın en büyük engeli batarya sorunu olabilir. ENH hatlarından beslenen bir şarj sistemi ile memleketimizin ENH denetimi 24 saat devriye atan İHA'lar ile etkili bir şekilde gerçekleştirilebilir.

En azından insanların gidemediği geçit, uçurum, sel, heyelan, deprem bölgelerinde, radyasyonlu alanlarda ya da salgın hastalık durumlarında ENH'ı, İHA ile kontrol edilebilir.

\section{ÇATIŞMA BEYANI}

Herhangi bir çıkar çatışması bulunmamaktadır.

\section{KAYNAKÇA}

Alptekin A, Çelik M Ö, Doğan Y \& Yakar M (2019). Mapping of a rockfall site with an unmanned aerial vehicle. Mersin Photogrammetry Journal, 1(1), 12-16.

Alptekin A, Çelik M Ö, Kuşak L, Ünel F B \& Yakar M (2019). Anafi Parrot'un Heyelan Bölgesi Haritalandırılmasında Kullanımı. Türkiye İnsansız Hava Araçları Dergisi, 1(1), 33-37.

Chen C, Yang B, Song S, Peng X \& Huang R (2018). Automatic clearance anomaly detection for transmission line corridors utilizing UAV-Borne LIDAR data. Remote Sensing, 10(4), 613.

Çelik M Ö, Yakar İ, Hamal S N G, Oğuz G M \& Kanun E (2020). Sfm Tekniği ile Olușturulan 3B Modellerin Kültürel Mirasın Belgelenmesi Çalışmalarında Kullanılması: Gözne Kalesi Örneği. Türkiye İnsansız Hava Araçları Dergisi, 2(1), 22-27.

Deng C, Wang S, Huang Z, Tan Z \& Liu J (2014). Unmanned aerial vehicles for power line inspection: A cooperative way in platforms and communications. J. Commun, 9(9), 687-692.

Erbaş M (2016). LiDAR Verilerinden Enerji Nakil Hatlarının Otomatik Tespit Edilmesi Çalışmaları. Harita Dergisi 156. Sayı 32-40

Guan H, Yu Y, Li J, Ji Z \& Zhang Q (2016). Extraction of power-transmission lines from vehicleborne lidar data. International Journal of Remote Sensing, 37(1), 229-247.

Jaugilas J (2019) Charging a rechargeable battery of an unmanned aerial vehicle in flight using a high voltage power line. U.S. Patent Application No 16/193,178.

Kabadayı A, Kaya \& Yiğit A Y (2020). Comparison of documentation cultural artifacts using the 3D model in different software. Mersin Photogrammetry Journal, 2(2), 51-58.

Karabörk H, Göktepe A, Yılmaz H M, Mutluoğlu Ö, Yıldız F \& Yakar M (2009). Tarihi ve kültürel varlıkların lazer tarama ve lazer nokta ölçme teknolojileri ile 3B modellenmesinde duyarlılık araştırması ve uygulama modelinin belirlenmesi. 12. Türkiye Harita Bilimsel ve Teknik Kurultayı, 11-15.

Kaya Y, Yiğit A Y, Ulvi A \& Yakar M (2021). Arkeolojik Alanların Dokümantasyonununda Fotogrametrik Tekniklerinin Doğruluklarının Karşılaştırmalı Analizi: Konya Yunuslar Örneği. Harita Dergisi, 165, 57-72.

Luque-Vega L, Castillo-Toledo B, Loukianov A \& Gonzalez-Jimenez L E (2014, April). Power line inspection via an unmanned aerial system based on the quadrotor helicopter. In MELECON 2014-2014 17th IEEE Mediterranean electrotechnical conference (pp. 393-397). IEEE.

Mirdan 0 \& Yakar M (2017). Tarihi eserlerin İnsansız Hava Aracı ile modellenmesinde karşılaşılan sorunlar. Geomatik, 2(3), 118-125.

Shen X, Qian C, Du Y, Yu X \& Zhang R (2018). An automatic extraction algorithm of high voltage transmission lines from airborne LIDAR point cloud data. Turkish Journal of Electrical Engineering \& Computer Sciences, 26(4), 20432055. 
Şasi A \& Yakar M (2018). Photogrammetric modelling of hasbey dar'ülhuffaz (masjid) using an unmanned aerial vehicle. International Journal of Engineering and Geosciences, 3(1), 611.

Teng G E, Zhou M, Li C R, Wu H H, Li W, Meng F R \& Ma L (2017). Mini-UAV LiDAR for power line inspection. Int. Arch. Photogramm. Remote Sens. Spat. Inf. Sci, 297-300.

Ulvi A, Yakar M, Yiğit A Y \& Kaya Y (2020). İHA ve Yersel Fotogrametrik Teknikler Kullanarak Aksaray Kızıl Kilise'nin 3 Boyutlu Nokta Bulutu ve Modelinin Üretilmesi. Geomatik Dergisi, 5(1), 22-30.

Ulvi A, Yakar M, Yiğit A \& Kaya Y (2019). The Use of Photogrammetric Techniques in Documenting Cultural Heritage: The Example of Aksaray Selime Sultan Tomb. Universal Journal of Engineering Science, 7(3), 64-73.

Yakar M, Kabadayı A, Yiğit A Y, Çıkıkcı K, Kaya Y \& Catin S S (2016). Emir Saltuk Kümbeti Fotogrametrik Rölöve Çalișmasi Ve 3Boyutlu Modellenmesi. Geomatik, 1(1), 14-18.

Yiğit A Y \& Ulvi A (2020). İHA Fotogrametrisi Tekniği Kullanarak 3B Model Olușturma: Yakutiye Medresesi Örneği. Türkiye Fotogrametri Dergisi, 2(2), 46-54.

Yiğit A Y \& Uysal M (2019). Nesne Tabanlı Sınıflandırma Yaklaşımı Kullanılarak Yolların Tespiti. Türkiye Fotogrametri Dergisi, 1(1), 17 24.

Yiğit A Y, Orhan O \& Ulvi A (2020). Investigation of The Rainwater Harvesting Potential at the Mersin University, Turkey. Mersin Photogrammetry Journal, 2(2), 64-75.

Polat N \& Kaya Y (2021) Çok Bantlı Uydu Görüntüleriyle Orman Yangınlarının Belirlenmesi ve Hasar Tespiti. Bartın Orman Fakültesi Dergisi, 23(1): 172-181. DOI: https://doi.org/10.24011/barofd.837507

Kaya Y \& Polat N (2021) Bitki İndeksleri Kullanarak Buğday Bitkisinin Rekolte Tahmini. Dicle Üniversitesi Mühendislik Fakültesi Mühendislik Dergisi, 12(1), 99-110. DOI: https://doi.org/10.24012/dumf.860325

Şenol H I, Erdogan S, Onal M, Ulukavak M, Memduhoglu, A, Mutlu S \& Yilmaz M (2017). 3D Modeling of a Bazaar in Ancient Harran City Using Laser Scanning Technique. International Archives of The Photogrammetry, Remote Sensing \& Spatial Information Sciences, 42.

Şenol H İ \& Kaya Y (2019). İnternet Tabanlı Veri Kullanımıla Yerleşim Alanlarının Modellenmesi: Çiftlikköy Kampüsü Örneği. Türkiye Fotogrametri Dergisi, 1(1), 11-16.

Şenol H İ, Memduhoglu A \& Ulukavak M (2020). Multi instrumental documentation and 3D modelling of an archaeological site: a case study in Kizilkoyun Necropolis Area. Dicle Üniversitesi Mühendislik Fakültesi Mühendislik Dergisi, 11(3), 1241-1250.

URL-1.

https://www.elektrikport.com/teknikkutuphane/

[Erișim Tarihi: 30.04.2020]

URL-2.

http://cografyaharita.com/turkiye_enerji_haritalari. html

[Erişim Tarihi: 01.05.2020]

URL-3. https://www.elektrikde.com/koronadesarji-korona-etkisi-nedir/

[Erișim Tarihi: 02.05.2020]

URL-4.

http://www.pmepowersolutions.com/lidar_p mepowersolutions.php

[Erişim Tarihi: 18.03.2020]

URL-5.

http://paksoyteknik.com.tr/images/PAKSOYTOPCON/IHA

[Erişim Tarihi: 19.03.2020]

URL-6. Sistem AS

https://www.youtube.com/watch?v=LzFXLI4y 3vQ\&feature=emb_rel_pause

[Erişim Tarihi: 03.05.2020]

URL-7.

https://www.greenvalleyintl.com/applications /power-line-inspection-using-airborne-lidar/

[Erişim Tarihi: 03.05.2020]

URL-8.

https://www.youtube.com/watch?v=DhMwNUmp8I

[Erişim Tarihi: 03.05.2020]

URL-9.

https://www.greenvalleyintl.com/applications/po wer-line-inspection-using-airborne-lidar/

[Erişim Tarihi: 20.03.2020]

URL-10.

http://tadviser.com/index.php/Product:LineRange r_\%28the_robot_for_the_power_transmission_line $\%$ 29

[Erişim Tarihi: 05.05.2020]

URL-11. https://www.mto.com.tr/singlepost/Yildirimdan-Korunma-Yuksek-Gerilim-EnerjiNakil-Hatlari\#!

[Erişim Tarihi: 05.05.2020]

URL-12. https://www.aisc.aero/avoidingpower-lines-while-flying-your-uav/

[Erişim Tarihi: 05.05.2020]

URL-13. http://raveneng.ca/

[Erişim Tarihi: 06.05.2020] 